\title{
Sub-erythemal ultraviolet radiation reduces metabolic dysfunction in already overweight mice
}

\author{
Naomi Fleury', Martin Feelisch², Prue H Hart', Richard B Weller³, Jordan Smoothy', \\ Vance B Matthews ${ }^{4}$ and Shelley Gorman ${ }^{1}$
}

${ }^{1}$ Telethon Kids Institute, University of Western Australia, Perth, Australia ${ }^{2}$ Clinical and Experimental Sciences, Faculty of Medicine, University of Southampton, Southampton General Hospital, Southampton, UK

3University of Edinburgh, MRC Centre for Inflammation Research, Edinburgh, Scotland

${ }^{4}$ School of Medicine and Pharmacology - Royal Perth Hospital Unit, The University of Western Australia,

Perth, Australia

Correspondence should be addressed to S Gorman Email shelley.gorman@ telethonkids.org.au

\begin{abstract}
Exposure to sunlight may limit cardiometabolic risk. In our previous studies, regular exposure to sub-erythemal (non-burning) ultraviolet radiation (UVR) reduced signs of adiposity and cardiometabolic dysfunction in mice fed a high-fat diet. Some of the observed effects were dependent on skin release of nitric oxide after UVR exposure. Here, we examine the effects of sub-erythemal UVR on signs of adiposity and metabolic dysfunction in already overweight mice, comparing the effects of two sunlamps with distinct emitted light spectra. Mice were fed a high-fat diet from 8 weeks of age, with UVR administered twice a week from 14 weeks of age until they were killed at 20 weeks of age. Mice were irradiated with the same dose of UVB radiation $\left(1 \mathrm{~kJ} / \mathrm{m}^{2}\right)$ from either FS40 ( $65 \%$ UVB, 35\% UVA) or CLEO (4\% UVB, 96\% UVA) sunlamps, but substantially more UVA from the latter. FS40 UVR (but not CLEO UVR) significantly reduced mouse weights and weight gain, compared to mice fed a high-fat diet (only). These effects were dependent on nitric oxide. Conversely, CLEO UVR (but not FS40 UVR) significantly reduced circulating LDL cholesterol. Both light sources reduced fasting insulin levels, and the extent of hepatic steatosis; the latter was reversed by topical application of CPTIO, suggesting an important role for skin release of nitric oxide in preventing hepatic lipid accumulation. These results suggest that there may be a number of benefits achieved by regular exposure to safe (non-burning) levels of sunlight or UV-containing phototherapy, with effects potentially dependent on the predominance of the wavelengths of UVR administered.
\end{abstract}

Key Words
obesity
cardiometabolic
dysfunction
- mice
- high-fat diet
- ultraviolet radiation
nitric oxide

Journal of Endocrinology

(2017) 233, 81-92

\section{Introduction}

Controlling the development of obesity and its comorbidities like metabolic syndrome and type- 2 diabetes is now the centerpiece of many government health strategies around the world. Although there is ongoing focus on energy-rich diets and insufficient exercise, there is an underappreciated potential for inadequate exposure to sunlight as an additional lifestyle modifier. There is evidence from human and preclinical

Published by Bioscientifica Ltd. 
studies that increased exposure to sunlight or ultraviolet radiation (UVR) may prevent the development of obesity and metabolic dysfunction.

In temperate climates that experience seasonal variation in ambient UVR levels, reduced blood pressure (Kunes et al. 1991, Woodhouse et al. 1993), heart failure, thromboembolic events and stroke have been observed in summer (reviewed in Zittermann \& Gummert 2010). Winter increases in body fat and plasma HbA1c have been reported in type 2 diabetics (Sohmiya et al. 2004). Other studies report that the incidence of type 2 diabetes and fasting glucose levels are lowest in summer (Doro et al. 2008). Positive latitude (distance from the equator) gradients, a surrogate for reduced sun exposure, have been reported for hypertension (Rostand 1997) and cardiovascular-related mortality (Baldassarre et al. 2010). Some studies also report a reduced risk of diabetes or obesity in people living at higher altitudes (reviewed in Hirschler 2016), where terrestrial UVB radiation levels are greater (Holick et al. 2007). Not all evidence from studies of season, latitude and altitude point to a protective effect of increased sun exposure on cardiometabolic disease risk (Rostand 1997, Shore-Lorenti et al. 2014, Hirschler 2016).

Other human studies have found inverse associations of obesity and outcomes of excessive sun exposure like skin cancer, even after adjusting for physical activity (Pothiawala et al. 2012, Tang et al. 2013). However, increased systolic blood pressure and risk of diabetes was observed in Korean adults obtaining $>5 \mathrm{~h}$ /day of sun exposure, who were older, more likely to be smokers and drink alcohol and less likely to have a college education (Ohn et al. 2014). In other epidemiological studies, women with active sunbathing habits or who used sun beds had reduced risk of type 2 diabetes (Lindqvist $e t$ al. 2010), thromboembolic events (Lindqvist et al. 2009) and all-cause mortality (Lindqvist et al. 2014) after adjusting for exercise and other confounders. Exposure to sub-erythemal UVA radiation reduced blood pressure in normotensive young (Liu et al. 2014) but not older adults (Krause et al. 1998, Scragg et al. 2011). The antihypertensive effects of UVA radiation may have been dependent on the release of nitric oxide from preformed skin stores (Liu et al. 2014). Two weeks of whole body treatments with erythemal UVB radiation (4 times in total) increased insulin secretion in healthy adults challenged with glucagon (Colas et al. 1989).

Vitamin D status can be used as a proxy for sun exposure. Skin exposure to UVB radiation results in dermal synthesis of vitamin $\mathrm{D}$, and further hydroxylation events in the liver increase circulating 25-hydroxyvitamin
D (25(OH)D). Vitamin D deficiency has been proposed as a risk factor for obesity and type 2 diabetes (Earthman et al. 2012). Serum 25(OH)D levels are reduced in obesity (Autier et al. 2014), but clinical trials have failed to conclusively show that vitamin D supplementation reduces weight gain (Mallard et al. 2016), type 2 diabetes or cardiovascular disease risk (Autier et al. 2014). The lack of success of these trials may be attributable to factors around study design (e.g. small sample size), the initial vitamin D status of participants (e.g. not being vitamin D-deficient at the start of the trial) and the amount and timing of vitamin D supplementation; however, the biological activity of non-vitamin $\mathrm{D}$ sun-induced mediators like nitric oxide (Feelisch et al. 2014, Liu et al. 2014, Fleury et al. 2016) may also explain the lack of effects observed.

We previously reported a protective effect of ongoing exposure to sub-erythemal UVR in controlling the development of signs of obesity and type 2 diabetes in $\mathrm{C} 57 \mathrm{Bl} / 6$ mice fed a high-fat diet (Geldenhuys et al. 2014). UV-irradiated mice had reduced weight gain and diminished metabolic dysfunction including decreased fasting glucose and insulin levels, improved glucose tolerance, reduced insulin resistance and less liver steatosis (Geldenhuys et al. 2014). The beneficial effects of UVR on fasting glucose levels and liver steatosis were at least partially dependent on skin release of nitric oxide (Geldenhuys et al. 2014). We exposed mice to sub-erythemal UVR twice a week, from a source (FS40 sunlamps) that mainly emitted UVB radiation, for the 12 weeks from when mice first started eating the high-fat diet (Geldenhuys et al. 2014). In the study described below, we tested exposure to UVR as a potential way to limit the progression of overweight to obesity. We concentrated on sub-erythemal (non-burning) UVR, which is of low risk for skin cancer development and therefore could more easily be translated into policy or therapy. We compared the effects of the FS40 sunlamps ( 65\% UVB), with a light source that emits radiation that more closely mimics sunlight (Cleo sunlamps, 4\% UVB (de Winter et al. 2001, Narbutt et al. 2005)). Finally, we examined a possible role for nitric oxide in mediating the effects of UVR.

\section{Materials and methods}

\section{Mice}

All experiments were performed according to the ethical guidelines of the National Health and Medical Research Council of Australia and with approval from the Telethon

Published by Bioscientifica Ltd. 
Kids Institute Animal Ethics Committee. C57Bl/6J(ARC) male mice were purchased from the Animal Resources Centre, Western Australia. The temperature $\left(21^{\circ} \mathrm{C}\right)$ and lighting conditions (12-h light/darkness cycle) in the animal facility were controlled. Mice were housed under Perspex-filtered fluorescent lighting, which emitted no detectable ultraviolet (UV) B radiation as measured using a UV radiometer (UVX Digital Radiometer, Ultraviolet Products Inc., Upland, CA, USA). Mice were allowed access to food and acidified water ad libitum.

\section{Diet}

All diets were obtained from Specialty Feeds (Glen Forrest, Western Australia). The contents of these semi-pure low- (5\% fat; canola oil) and high-fat (23\%; lard (20.7\%)) diets are described in Supplementary Table 1 (see section on supplementary data given at the end of this article). Neither diet was supplemented with dietary vitamin D, as the effects of UVR were reduced by this treatment in previous studies (Geldenhuys et al. 2014). Serum 25-hydroxyvitamin $\mathrm{D}$ levels in response to irradiation of $\mathrm{C} 57 \mathrm{Bl} / 6 \mathrm{~J}$ male mice to the same frequency (twice a week) and dose $\left(1 \mathrm{~kJ} / \mathrm{m}^{2}\right)$ of UVB radiation from the FS40 sunlamps (as that used here, see below) have previously been reported in detail (Geldenhuys et al. 2014). All mice were fed the low-fat diet from 4 until 8 weeks of age, and one group was fed the low-fat diet until the end of the experiment. All other mice were fed the high-fat diet from 8 weeks of age for 12 weeks until mice were 20 weeks of age (Fig. 1).
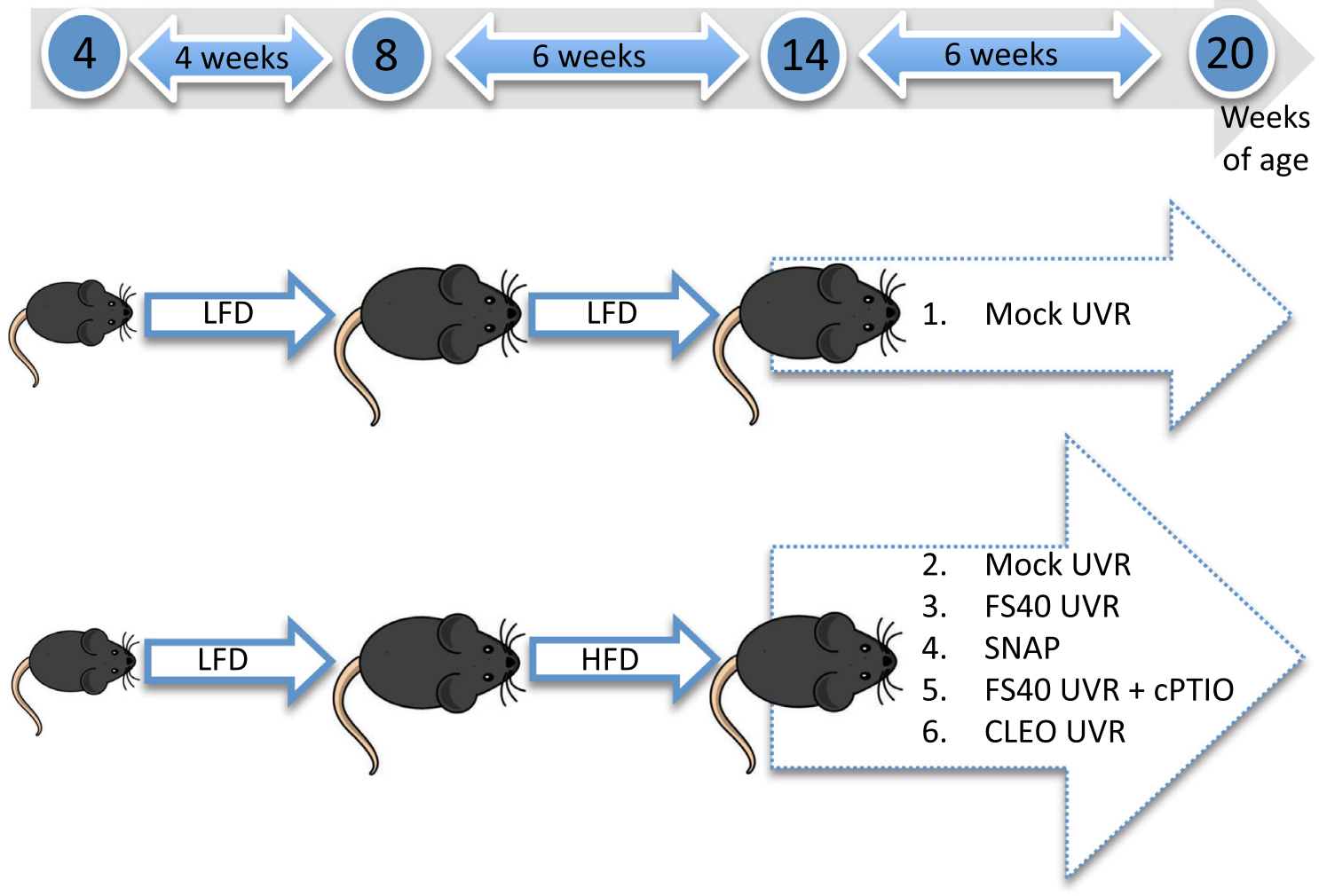

Figure 1

The experimental approach. Four-week-old C57BI/6J male mice were fed a low-fat diet (LFD) for four weeks. At eight weeks of age, mice were either continued on this diet (treatment 1) or switched to a high-fat diet (HFD). After 6 weeks of feeding, mice fed the HFD were exposed to one of 5 treatments for another 6 weeks. The shaved dorsal skin of these mice were treated twice a week with (2) vehicle only and mock-irradiation (Mock UVR), (3) sub-erythemal FS40 UVR (1 kJ/m² UVB) and then vehicle (FS40 UVR), (4) topical SNAP (SNAP), (5) sub-erythemal FS40 UVR (1 kJ/m² UVB) and then topical CPTIO (FS40 UVR + CPTIO) or (6) CLEO UVR (1 kJ/m² UVB; CLEO UVR). The first treatment group of mice (1) were fed a low-fat diet and were administered the vehicle and mock-irradiated twice a week. Mice were treated for 6 weeks with these skin treatments until 20 weeks of age. There were a total of 6 treatments, with 18 mice per treatment. The experiment was performed twice with results combined for both experiments. nb. One mouse was killed from the CLEO UVR treatment (at week 4), and another from the FS40 UVR + CPTIO treatment (at week 10) due to the development of severe dermatitis, which did not resolve, reducing the total number of animals to 17 in these two groups.

http://joe.endocrinology-journals.org DOI: 10.1530/JOE-16-0616
๑) 2017 Society for Endocrinology Printed in Great Britain
Published by Bioscientifica Ltd 


\section{UV radiation and topical skin treatments}

Two sources of UVR were used. The first was a bank of $40 \mathrm{~W}$ FS40 lamps (Philips TL UV-B, Eindhoven, The Netherlands) emitting broadband UVR, $250-360 \mathrm{~nm}$, with $65 \%$ of the output in the UVB range ( $280-315 \mathrm{~nm}$ ), and the remaining UVR in the UVC (250-280 nm) and UVA (315$360 \mathrm{~nm})$ ranges. The second was a bank of $100 \mathrm{~W}$ Cleo Natural lamps (Philips) emitting light, which more closely mimics the terrestrial spectrum of solar radiation, with the spectral UVR bandwidth composed of $4 \%$ UVB and $96 \%$ UVA (de Winter et al. 2001, Narbutt et al. 2005). Cleanshaven dorsal skin $\left(8 \mathrm{~cm}^{2}\right)$ was exposed to light emitted from either the FS40 or CLEO sunlamps as previously described using PVC plastic to block wavelengths less than $280 \mathrm{~nm}$ (UVC radiation) (Gorman et al. 2007, $\mathrm{Ng}$ et al. 2013, Geldenhuys et al. 2014). Mice exposed to either light source were irradiated with the same dose of sub-erythemal UVB radiation $\left(1 \mathrm{~kJ} / \mathrm{m}^{2}\right.$; (McGlade et al. 2007, Geldenhuys et al. 2014)) as determined using a handheld ultraviolet radiometer (UVX Digital Radiometer; Ultraviolet Products Inc.). The amount of UVA radiation delivered differed, with mice receiving an estimated dose of 0.5 or $24 \mathrm{~kJ} / \mathrm{m}^{2}$ of UVA radiation, when exposed to the FS40 or CLEO lamps, respectively. For other treatments, as previously described (Geldenhuys et al. 2014), dorsal skin was treated with $0.1 \mathrm{mmol}$ SNAP (S-nitroso-N-acetyl-D,Lpenicillamine, Sigma (Ikeyama et al. 2007)), a nitric oxide donor or a nitric oxide scavenger, cPTIO (carboxy-PTIO potassium salt, Sigma (Yasukawa et al. 2012), $0.1 \mathrm{mmol}$ ) immediately following delivery of FS40 UVR. For mock treatments, the dorsal skin of mice was shaved, and mice then placed in the same Perspex box (under standard fluorescent lighting) for the same amount of time used to irradiate other mice. After 6 weeks of feeding mice the high-fat diet (Fig. 1), one of five of the following skin treatments was administered twice a week to the shaved dorsal skin of mice: (1) vehicle and mock-irradiation (Mock UVR), (2) sub-erythemal FS40 UVR ( $\left.1 \mathrm{~kJ} / \mathrm{m}^{2} \mathrm{UVB}\right)$ and then vehicle (FS40 UVR); (3) topical SNAP (1 mM, SNAP); (4) sub-erythemal FS40 UVR $\left(1 \mathrm{~kJ} / \mathrm{m}^{2} \mathrm{UVB}\right)$ and then topical cPTIO (FS40 UVR + CPTIO) or (5) CLEO UVR ( $1 \mathrm{~kJ} / \mathrm{m}^{2} \mathrm{UVB}$; CLEO UVR) (Fig. 1). The SNAP-treated mice were also mock-irradiated. A final group of mice were fed the low-fat diet and treated with vehicle and mockirradiated twice a week.

\section{Measuring weight gain and tissue weights}

Mice were weighed weekly on the same day in the morning using a digital scale (Ohaus Scout, $>0.1 \mathrm{~g}$ resolution).
Percentage weight gain was calculated from 8 weeks of age. At the conclusion of the experiment, liver and gonadal deposits of white adipose tissue and interscapular deposits of brown adipose tissue were dissected from mice and their weights were determined using an analytical scale (Analytical Standard Electric Balance, Ohaus, NJ, USA; $>0.0001$ g resolution).

\section{Glucose tolerance tests (GTT)}

As previously described (Geldenhuys et al. 2014), but briefly, mice were fasted for $5 \mathrm{~h}$ before injected intraperitoneally with $1 \mathrm{~g} / \mathrm{kg}$ glucose (Phebra, Lane Cove, NSW, Australia), with glucose levels serially monitored before and after the glucose challenge using a Accu-Chek Performa glucometer (Roche).

\section{Serum metabolites}

Serum cholesterol, HDL cholesterol, LDL cholesterol and triglyceride and fasting insulin, adiponectin and leptin were measured as previously described (Geldenhuys et al. 2014). Serum levels of activated aspartate aminotransferase (AST) levels were measured at PathWest Pathology, using the Clinical Chemistry kit as part of the Architect $c$ System (Abbot Laboratories).

\section{Histopathological assessment of liver pathology}

The severity of non-alcoholic fatty liver disease (NAFLD) was assessed by grading formalin-fixed and H\&E-stained liver sections as previously described (Geldenhuys et al. 2014), with the extent of fibrosis scored in Masson's trichrome-stained sections $(0=$ none, $1=$ fibrosis in some portal areas, $2=$ fibrosis in most portal areas, $3=$ fibrosis in most portal areas with portal to portal bridging, $4=$ fibrosis in most portal areas with portal to central bridging) (Kleiner et al. 2005). Steatosis and ballooning scores were added together for an overall steatosis score ( $\leq 6$, (Geldenhuys et al. 2014)), and fibrosis scores were added to these for a combined histopathology score $(\leq 10)$.

\section{Statistical analyses}

The experiment was performed twice, with $n=18$ mice per treatment. Initial power calculations indicated that 36 mice per group would be required to observe a significant reduction of $\geq 35 \%$ in weight gain (power $\geq 0.8, P<0.05$; $G^{*}$ Power v3.1.3, 2009, based upon previously published data (Geldenhuys et al. 2014)). However, this number of

Published by Bioscientifica Ltd. 
mice per group exceeded the logistical capacity of our research team. We expected that using an inbred strain under identical maintenance conditions would produce comparable results, and so, split this large experiment into two of equal size. Within the controlled confines of a single animal house, we controlled for the potential effects of seasonality (in particular temperature and lighting fluctuations), important factors in studying the effects of UVR on biological responses. Experiment 1 commenced in February 2015 and was completed in June 2015, whereas experiment 2 commenced in April 2015 and was completed in August 2015. The combined results from both experiments were compared using an analysis of variance (ANOVA) comparing between treatments using a Tukey post hoc analysis, which corrects for multiple comparisons. Area under the curve (AUC) was calculated for GTT using GraphPad Prism (v5) using 0 as the baseline. Results were considered as statistically significant for $P$ values $<0.05$.

\section{Results}

\section{A high-fat diet induced signs of overweight and metabolic dysfunction after 6 weeks of feeding}

C57BL/6J male mice were fed a high- or low-fat diet from 8 weeks of age onward (Fig. 1). Mice fed the highfat diet weighed more (Fig. 2A) and had increased weight gain (Fig. 2B) than those fed the low-fat diet after
1-2 weeks of feeding, weighing considerably more after 6 weeks. A GTT was performed after 5 weeks. Impaired glucose tolerance was observed in mice fed the highfat diet with increased blood glucose levels observed at various times after glucose challenge (Fig. 2C), and increased AUC (GTT, Fig. 2D) observed in mice fed a high-fat diet.

\section{FS40 UVR but not CLEO UVR reduced weights and weight gain in mice fed a high-fat diet}

After 6 weeks of feeding mice the high-fat diet, one of five skin treatments was administered twice a week to the shaved dorsal skin of mice as described in Fig. 1. Another group of mice were fed the low-fat diet and treated with vehicle and mock-irradiated twice a week. All mice fed the high-fat diet weighed more (Fig. 3A and C) and gained more weight (Fig. 3B and D) than those fed the low-fat diet after 84 days (12 weeks) of feeding. Mice treated with FS40 UVR (but not CLEO UVR) had significantly reduced weights and weight gain compared to mice fed the high-fat diet after 6 weeks of treatment (Fig. 3). There was no difference in weights or weight gain after topical application of the nitric oxide donor SNAP (and feeding mice a high-fat diet), compared to mice fed a high-fat diet (and mock treated) (Fig. 3). Topical treatment with the nitric oxide scavenger, CPTIO, prevented the suppressive effects of FS40 UVR on body weights and weight gain (Fig. 3).
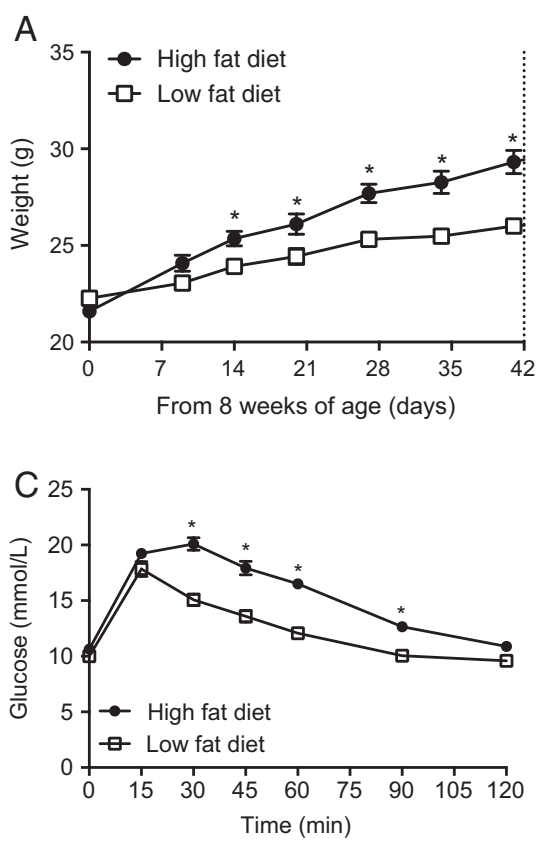

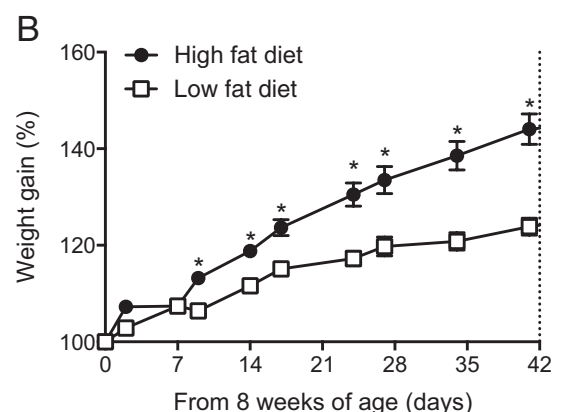

$\mathrm{D}$

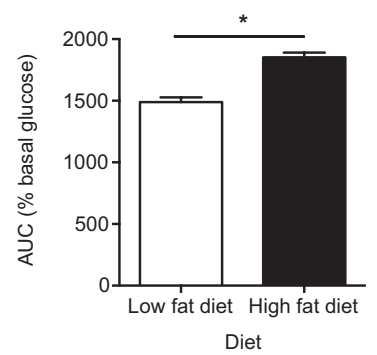

Figure 2

A high-fat diet significantly increased weight gain and signs of glucose intolerance after 6 weeks of feeding. Four-week-old C57BI/6J male mice were fed a low-fat diet for four weeks. At eight weeks of age, mice were either continued on this diet (treatment 6) or switched to a high-fat diet (treatments 1-5). Data are shown as mean $\pm /+$ S.E.M. for $n=35-36$ mice/treatment (weights), $n=18-20$ mice/treatment (GTT). After 6 weeks of feeding, body weights (A) and percentage weight gain (B) are shown. A glucose tolerance test (GTT) was performed on subsets of mice after 5 weeks of feeding (respectively) and involved fasting the mice for $5 \mathrm{~h}$, challenging them with glucose and measuring glucose levels serially for $2 \mathrm{~h}$. The curves for the GTT are shown in (C), and the area under the curve (AUC) for these results is shown in (D), respectively. ${ }^{*} P<0.05$. (c) 2017 Society for Endocrinology Printed in Great Britain 
A
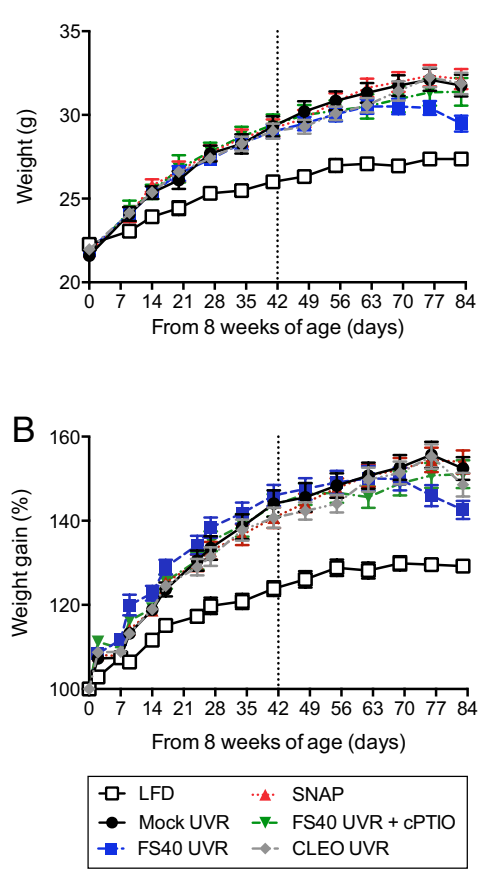

C

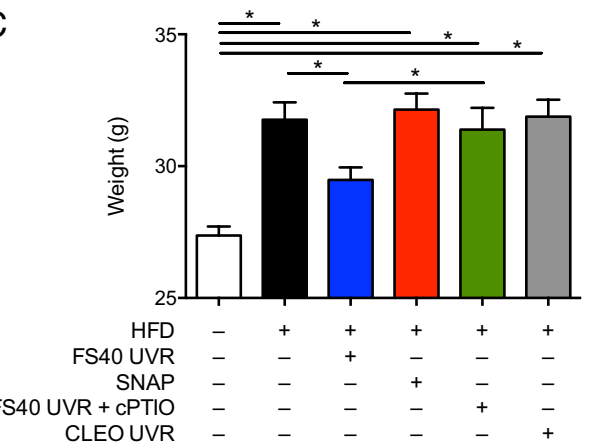

D

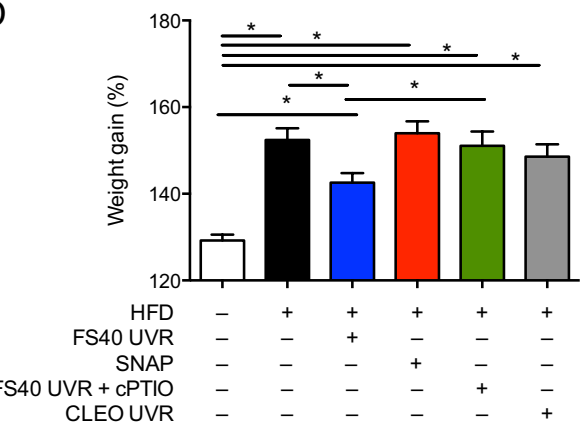

\section{Figure 3}

The effects of chronic UVR on weights and weight gain in 'overweight' mice fed a high-fat diet. The experiment is described in detail in Fig. 1. In panels (A) and (B), a broken vertical line was used to indicate when the skin treatments began. Data are shown as mean $\pm /+$ S.E.M. for $n=35-36$ mice/treatment. In (A), body weights and in (B) percentage weight gain is shown for mice weighed between 8 and 20 weeks of age (for 12 weeks). In (C) body weights and in (D) percentage weight gains at the 12 -week endpoint are shown. ${ }^{*} P<0.05$.

\section{UVR reduced fasting insulin levels in mice fed a} high-fat diet

Mice fed the low-fat diet had significantly reduced fasting insulin and leptin levels in comparison to mice fed the high-fat diet only (mock UVR + vehicle) (Table 1) after 3 weeks of the skin interventions (or after 9 weeks of being fed a high-fat diet). Reduced fasting insulin levels were observed in mice exposed to UVR from either sunlamp (FS40 or CLEO), compared to those in mice fed a highfat diet only (Table 1). However, there was no difference between fasting insulin levels observed in mice exposed to FS40 UVR, with or without cPTIO treatment (Table 1). There was no difference in adiponectin levels measured in mice from any treatment (Table 1). Mice fed the low-fat diet had significantly improved glucose tolerance (as measured by GTT) compared to mice fed the high-fat diet only (mock UVR + vehicle) (Table 1) after 4 weeks of the skin interventions (or after 10 weeks of being fed a high-fat diet). However, none of the UVR and/or topical treatments affected the extent of glucose intolerance observed or fasting glucose levels when comparing results observed in mice fed the high-fat diet only (Table 1).

\section{CLEO UVR reduced serum LDL cholesterol levels in mice fed a high-fat diet}

At the end of the experiment (and after 6 weeks of the skin interventions), LDL cholesterol levels were reduced in mice from the CLEO UVR (high-fat diet) and low-fat

Table 1 Expression levels of fasting insulin, leptin, adiponectin and glucose, and area under the curve values for glucose tolerance tests (GTT) measured 9-11 weeks after mice were initially fed the high-fat diet.

$\begin{array}{llll} & & & \begin{array}{l}\text { UVR and/or skin } \\ \text { treatment }\end{array} \\ 1 & \text { Diet } & \text { LFD } & \text { Mock UVR + vehicle } \\ 2 & \text { HFD } & \text { Mock UVR + vehicle } \\ 3 & \text { HFD } & \text { FS40 UVR + vehicle } \\ 4 & \text { HFD } & \text { SNAP } \\ 5 & \text { HFD } & \text { FS40 UVR + CPTIO } \\ 6 & \text { HFD } & \text { CLEO UVR + vehicle } \\ \text { n/treatment }\end{array}$

\begin{tabular}{c}
$\begin{array}{c}\text { Fasting insulin } \\
(\mathrm{ng} / \mathrm{mL})\end{array}$ \\
\hline $\mathbf{0 . 5} \pm \mathbf{0 . 0} \mathbf{0}^{*}$ \\
$4.1 \pm 1.2^{+}$ \\
$\mathbf{1 . 2} \pm \mathbf{0 . 2}{ }^{*}$ \\
$1.8 \pm 0.4$ \\
$1.6 \pm 0.4$ \\
$\mathbf{1 . 2} \pm \mathbf{0 . 2} *$ \\
$10-12$ \\
\hline
\end{tabular}

\begin{tabular}{c}
$\begin{array}{c}\text { Fasting leptin } \\
(\mathrm{ng} / \mathrm{mL})\end{array}$ \\
\hline $\mathbf{1 . 0} \pm \mathbf{0 . 4}$ \\
$15.2 \pm 2.7^{\dagger}$ \\
$11.9 \pm 2.3^{\dagger}$ \\
$8.8 \pm 1.5^{\dagger}$ \\
$13.8 \pm 3.9^{\dagger}$ \\
$15.0 \pm 2.9^{\dagger}$ \\
$8-12$ \\
\hline
\end{tabular}

\begin{tabular}{c}
$\begin{array}{c}\text { Fasting glucose } \\
(\mathrm{mM})\end{array}$ \\
\hline $10.1 \pm 0.4$ \\
$10.1 \pm 0.3$ \\
$8.8 \pm 0.4$ \\
$9.1 \pm 0.4$ \\
$10.0 \pm 0.4$ \\
$9.5 \pm 0.3$ \\
$14-18$
\end{tabular}

GTT (AUC $\%$ basal glucose)

$1550+42 *$

$1973 \pm 62^{+}$

$1857 \pm 81^{+}$

$1915 \pm 65^{+}$

$2103 \pm 122^{\dagger}$

$1774 \pm 42$

$14-18$

* $\boldsymbol{P}<\mathbf{0 . 0 5}$ relative to HFD (mock UVR + vehicle), one-way ANOVA (Tukey post hoc analysis); ${ }^{\dagger} \boldsymbol{P}<0.05$ relative to LFD (mock UVR + vehicle), one-way ANOVA (Tukey post hoc analysis).

AUC, area under curve; CPTIO, carboxy-PTIO; HFD, high-fat diet; LFD, low-fat diet; SNAP, S-nitroso-N-acetyl-D,L-penicillamine; UVR, ultraviolet radiation.

http://joe.endocrinology-journals.org
DOI: $10.1530 / \mathrm{JOE}-16-0616$

๑ 2017 Society for Endocrinology Printed in Great Britain
Published by Bioscientifica Ltd. 
Table 2 Circulating lipid levels and adipose tissue weights at the end of the experiment.

\begin{tabular}{|c|c|c|}
\hline & Diet & $\begin{array}{l}\text { UVR and/or skin } \\
\text { treatment }\end{array}$ \\
\hline $\begin{array}{l}1 \\
2\end{array}$ & $\begin{array}{l}\text { LFD } \\
\text { HFD }\end{array}$ & $\begin{array}{l}\text { Mock UVR + vehicle } \\
\text { Mock UVR + vehicle }\end{array}$ \\
\hline 3 & HFD & FS40 UVR + vehicle \\
\hline 4 & HFD & SNAP \\
\hline 5 & HFD & FS40 UVR + CPTIO \\
\hline 6 & HFD & CLEO UVR + vehicle \\
\hline
\end{tabular}

\begin{tabular}{c}
$\begin{array}{c}\text { LDL cholesterol } \\
(\mathrm{mM})\end{array}$ \\
\hline $\mathbf{0 . 1 3} \pm \mathbf{0 . 0 1 *}$ \\
$0.22 \pm 0.01^{\dagger}$ \\
$0.20 \pm 0.02^{\dagger}$ \\
$0.19 \pm 0.01^{\dagger}$ \\
$0.18 \pm 0.02$ \\
$\mathbf{0 . 1 2} \pm \mathbf{0 . 0 1}$ \\
$14-17$ \\
\hline
\end{tabular}

\begin{tabular}{c}
$\begin{array}{c}\text { HDL cholesterol } \\
(\mathrm{mM})\end{array}$ \\
\hline $1.5 \pm 0.1$ \\
$1.7 \pm 0.1$ \\
$1.7 \pm 0.2$ \\
$1.7 \pm 0.1$ \\
$1.7 \pm 0.1$ \\
$1.6 \pm 0.1$ \\
$14-17$
\end{tabular}

\begin{tabular}{c}
$\begin{array}{c}\text { Total-cholesterol } \\
(\mathrm{mM})\end{array}$ \\
\hline $2.2 \pm 0.2$ \\
$3.0 \pm 0.2$ \\
$3.2 \pm 0.3^{\dagger}$ \\
$3.1 \pm 0.2^{\dagger}$ \\
$3.1 \pm 0.1$ \\
$2.6 \pm 0.1$ \\
$28-31$ \\
\hline
\end{tabular}

\begin{tabular}{c}
$\begin{array}{c}\text { Triglyceride } \\
(\mathrm{mM})\end{array}$ \\
\hline $0.9 \pm 0.1$ \\
$1.1 \pm 0.1$ \\
$0.8 \pm 0.1$ \\
$1.1 \pm 0.2$ \\
$0.9 \pm 0.0$ \\
$0.8 \pm 0.1$ \\
$14-17$ \\
\hline
\end{tabular}

\begin{tabular}{c}
\hline Gonadal WAT $(\mathrm{g})$ \\
\hline $\mathbf{0 . 6} \pm \mathbf{0 . 0 *}$ \\
$1.4 \pm 0.1^{\dagger}$ \\
$1.1 \pm 0.1^{\dagger}$ \\
$1.5 \pm 0.1^{\dagger}$ \\
$1.3 \pm 0.1^{\dagger}$ \\
$1.2 \pm 0.1^{\dagger}$ \\
$14-17$
\end{tabular}

\begin{tabular}{c}
$\begin{array}{c}\text { Inter-scapular } \\
\text { BAT }(\mathrm{g})\end{array}$ \\
\hline $0.15 \pm 0.01$ \\
$0.20 \pm 0.02$ \\
$0.15 \pm 0.01$ \\
$0.18 \pm 0.01$ \\
$0.17 \pm 0.02$ \\
$\mathbf{0 . 1 4} \pm \mathbf{0 . 0 1}$ * \\
$28-31$
\end{tabular}

* $\boldsymbol{P}<\mathbf{0 . 0 5}$ relative to HFD (mock UVR + vehicle), one-way ANOVA (Tukey post hoc analysis); ${ }^{\dagger} \boldsymbol{P}<0.05$ relative to LFD (mock UVR + vehicle), one-way ANOVA (Tukey post hoc analysis).

AUC, area under curve; BAT, brown adipose tissue; CPTIO, carboxy-PTIO; HDL, high-density lipoprotein; HFD, high-fat diet; LDL, low-density lipoprotein; LFD, low-fat diet; SNAP, S-nitroso-N-acetyl-D,L-penicillamine; UVR, ultraviolet radiation; WAT, white adipose tissue.

diet treatments compared to other treatment groups (Table 2). Weights of gonadal WAT were reduced in mice fed the low-fat diet, compared to high-fat diet treatments, with no significant reduction observed in mice exposed to UVR from either source (compared to the high-fat diet only treatment) (Table 2). Weights of interscapular BAT levels were significantly reduced in mice administered CLEO UVR (and fed a high-fat diet), compared to mice fed a high-fat diet only (Table 2). There was no effect of any of the skin treatments on serum triglyceride or HDL cholesterol or total cholesterol levels (Table 2).

\section{UVR reduced liver steatosis in mice fed a high-fat diet}

At the end of each experiment (or after 6 weeks of UVR intervention), significant steatosis and mild fibrosis were observed in livers of mice fed a high-fat diet (Fig. 4 and Table 3). Unexpectedly, there was significant steatosis in mice fed the low-fat diet, even though liver weights were significantly lower than those observed in mice fed a highfat diet only (Table 3). Mice fed a high-fat diet and also exposed to FS40 or CLEO UVR or topically treated with the nitric oxide donor (SNAP) had significantly reduced liver steatosis compared to mice fed a high-fat diet only (Fig. 4 and Table 3). The effects of FS40 UVR on liver steatosis were reversed by immediate treatment with the nitric oxide donor CPTIO (Table $3, P<0.05$ ). In addition, there was some evidence (a trend; $t$ test, $P=0.06$ ) that the FS40 UVR treatment reduced circulating levels of the liver function enzyme, aspartate aminotransferase (AST) when compared to levels observed in mice fed the highfat diet only (Table 3). Increased AST levels are generally
A

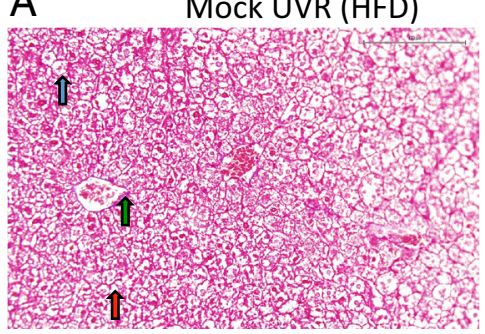

D

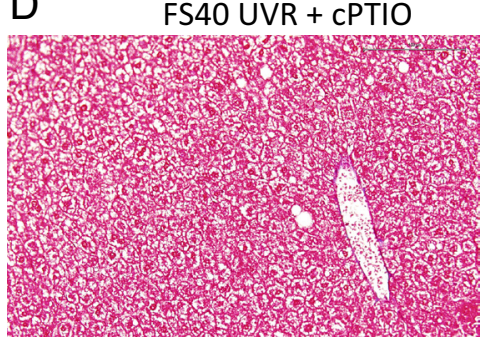

B

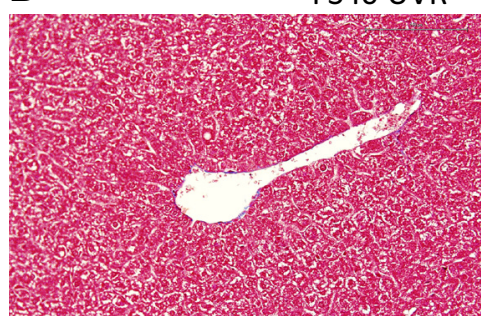

E

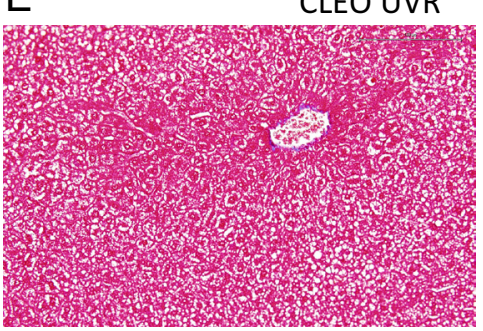

C

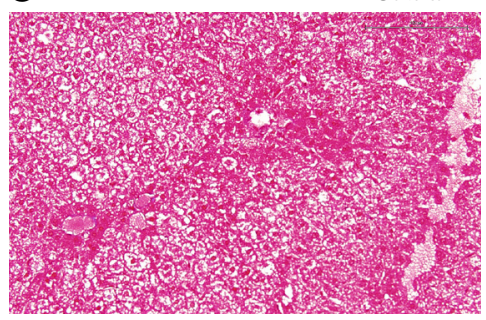

F

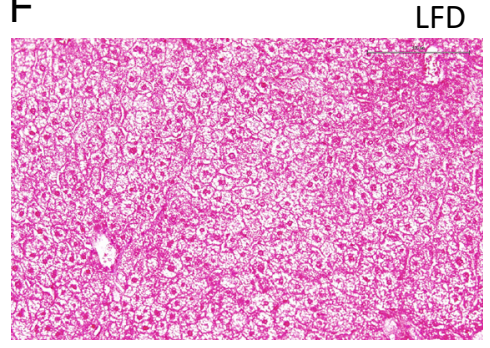

Figure 4

Representative liver histology sections stained with Masson's trichrome. The experiment is described in detail in Fig. 1. Data are representative of 2 experiments, with red arrows used to indicate steatosis, blue arrows for ballooning and green arrow for fibrosis for livers obtained at the 12-week endpoint.

http://joe.endocrinology-journals.org DOI: 10.1530/JOE-16-0616
๑ 2017 Society for Endocrinology Printed in Great Britain
Published by Bioscientifica Ltd 
regarded as an initial sign of liver dysfunction and may be used as part of a diagnosis of NAFLD (Clark 2006). There was less evidence for reduced AST levels $(P=0.2)$ in mice treated with UVR and cPTIO, compared to those in mice treated with UVR and vehicle (Table 3). Altogether, these results suggest that regular exposure to low-dose UVR may reduce signs of NAFLD in mice fed a high-fat diet through mechanisms, which may be partially dependent on nitric oxide.

\section{Discussion}

Here, we observed the beneficial effects of ongoing exposure to low-dose (sub-erythemal) UVR as an intervention to reduce the severity of metabolic dysfunction in overweight mice fed a high-fat diet. Both sources of UVR reduced fasting insulin levels and the extent of liver steatosis. Applying the nitric oxide scavenger cPTIO to skin prevented the beneficial effects of FS40 UVR on liver steatosis but not fasting insulin, suggesting that different mediator(s) induced by UVR may be responsible. Furthermore, CLEO UVR (or SNAP) had an additional benefit of reducing circulating LDL cholesterol levels. Those mice treated with UVR from the CLEO lamps were exposed to $\geq 10$-fold more UVA radiation (than emitted by FS40 sunlamps), suggestive of a suppressive role for UVA-induced mediators in curbing serum LDL cholesterol levels. UVR from FS40 (but not CLEO) sunlamps reduced body weight and weight gain in mice fed a high-fat diet. These effects were reversed by topical treatment with the nitric oxide donor, cPTIO, suggesting a dependence on skin release of nitric oxide induced by UVR from the FS40 sunlamps. Put together, these findings indicate a potential benefit for UVR and sun exposure in limiting weight gain and metabolic dysfunction induced by excessive weight gain and obesity.

There are a limited number of preclinical studies that report on the effects of ongoing exposure to UVR on weight gain and signs of metabolic dysfunction (Nakano et al. 2011, Geldenhuys et al. 2014). A strength of our preclinical approach is that we measured the direct effects of ongoing UVR exposure of a known dose. Sun exposure is not easy to quantify in humans, especially over the long time frame required for obesity development. In addition, many other factors can be readily controlled in animal studies, including genetics (inbred mice), environment (in particular temperature and duration of light/darkness cycles), diet and exercise, which are all considerably more challenging in human studies. Even so, a number of difficult-to-control factors could affect the results, which are hard to identify but may have included the effects of different batches of diet or mice, and where breeding may be seasonally affected. We also acknowledge that mice have different skin to humans, with substantially more hair/fur and a thinner epidermis. To test for potential translatability of results, it will therefore be important to reproduce the findings of this study in a human setting. Our findings are similar to those of Al-Daghir and coworkers, in which 59 adults from Saudi Arabia underwent a year-long intervention, which promoted sun exposure (5-30 min) two times a week and increased consumption of vitamin D-rich foods (Al-Daghri et al. 2012). The prevalence of metabolic syndrome reduced from $25 \%$ to $13 \%$, accompanied by reduced dyslipidemia (Al-Daghri et al. 2012). The participants of this study had an initial mean BMI of 29.2, suggesting that many were overweight and obese (Al-Daghri et al. 2012). Together with our new findings, these results suggest that low-level sun exposure may

Table 3 Liver weights and histopathology scores at the end of the experiment.

\begin{tabular}{|c|c|c|c|}
\hline & Diet & $\begin{array}{l}\text { UVR and/or skin } \\
\text { treatment }\end{array}$ & Liver weight $(\mathrm{g})$ \\
\hline $\begin{array}{l}1 \\
2\end{array}$ & $\begin{array}{l}\overline{\text { LFD }} \\
\text { HFD }\end{array}$ & $\begin{array}{l}\text { Mock UVR + vehicle } \\
\text { Mock UVR + vehicle }\end{array}$ & $\begin{array}{c}\mathbf{0 . 9 6} \pm \mathbf{0 . 0 3}{ }^{*} \\
1.20 \pm 0.04^{\dagger}\end{array}$ \\
\hline 3 & HFD & FS40 UVR + vehicle & $1.04 \pm 0.02 *$ \\
\hline 4 & HFD & SNAP & $1.03 \pm 0.03 *$ \\
\hline 5 & HFD & FS40 UVR + CPTIO & $1.08 \pm 0.04$ \\
\hline 6 & HFD & CLEO UVR + vehicle & $1.12 \pm 0.03^{\dagger}$ \\
\hline \multicolumn{3}{|c|}{$\mathrm{n} /$ treatment } & $29-31$ \\
\hline
\end{tabular}

\begin{tabular}{c}
\hline Steatosis score $(/ 6)$ \\
\hline $4.2 \pm 0.2$ \\
$4.6 \pm 0.1$ \\
$\mathbf{3 . 3} \pm \mathbf{0 . 1} *+$ \\
$\mathbf{3 . 7} \pm \mathbf{0 . 2}$ \\
$4.3 \pm 0.1$ \\
$\mathbf{3 . 7} \pm \mathbf{0 . 2} *$ \\
10
\end{tabular}

\begin{tabular}{c} 
Fibrosis score $(/ 4)$ \\
\hline $1.3 \pm 0.2$ \\
$1.8 \pm 0.2$ \\
$1.4 \pm 0.2$ \\
$1.7 \pm 0.5$ \\
$1.6 \pm 0.1$ \\
$1.4 \pm 0.3$ \\
10 \\
\hline
\end{tabular}

\begin{tabular}{c} 
Combined score $(/ 10)$ \\
\hline $\mathbf{5 . 4} \pm \mathbf{0 . 2 *}$ \\
$6.4 \pm 0.3^{\dagger}$ \\
$\mathbf{4 . 6} \pm \mathbf{0 . 2 *}$ \\
$\mathbf{5 . 4} \pm \mathbf{0 . 1 *}$ \\
$5.9 \pm 0.2^{*}$ \\
$\mathbf{4 . 9} \pm \mathbf{0 . 2}$ \\
10
\end{tabular}

\begin{tabular}{c} 
AST (U/L) \\
\hline $339 \pm 109$ \\
$226 \pm 62$ \\
$101 \pm 13$ \\
$310 \pm 109$ \\
$135 \pm 30$ \\
$162 \pm 37$ \\
12
\end{tabular}

* $\boldsymbol{P}<\mathbf{0 . 0 5}$ relative to HFD (mock UVR + vehicle), one-way ANOVA (Tukey post hoc analysis); ${ }^{\dagger} \boldsymbol{P}<0.05$ relative to LFD (mock UVR + vehicle), one-way ANOVA (Tukey post hoc analysis).

AST, aspartate aminotransferase; AUC, area under curve; CPTIO, carboxy-PTIO; HFD, high fat diet; LFD, low fat diet; SNAP, S-nitroso-N-acetyl-D,Lpenicillamine; UVR, ultraviolet radiation.

http://joe.endocrinology-journals.org DOI: 10.1530/JOE-16-0616
๑) 2017 Society for Endocrinology Printed in Great Britain
Published by Bioscientifica Ltd. 
reduce adiposity and improve cardiometabolic outcomes in overweight and/or obese people.

The protective effects of CLEO UVR in suppressing circulating LDL cholesterol levels are supported by studies in humans. Sun exposure for 15 days reduced the LDL/ HDL cholesterol ratio in the serum of adults with psoriasis undergoing heliotherapy (Osmancevic et al. 2009). Oxidized LDL cholesterol levels increased with latitude in men with stable coronary heart disease (Grau et al. 2007). Dietary administration of the eNOS substrate L-arginine to healthy elderly human volunteers for 2 weeks lowered circulating LDL but not HDL cholesterol levels (Hurson et al. 1995), suggesting that systemic elevation of nitric oxide exerts effects consistent with the ones we here observed with UVR. Combined with observations from the literature, our findings suggest that safe sun exposure might be a way of reducing serum LDL cholesterol levels in patients with cardiometabolic dysfunction.

The effects of FS40 UVR on weight, weight gain and liver steatosis were reversed by immediate skin treatment with the nitric oxide scavenger cPTIO, suggesting that skin release of nitric oxide mediates the protective effects of UVR on these signs of adiposity. In the current study, we did not observe all the effects of nitric oxide donor SNAP, as previously found, when it suppressed body weight and liver steatosis (Geldenhuys et al. 2014) (compared to only liver steatosis in the current study). A difference between these findings might be accounted for by reduced treatment time in the current study, whereas previously SNAP was administered to skin from when mice were first fed a high-fat diet (Geldenhuys et al. 2014). In addition, our results suggest that skin exposure to UVR is more effective (than SNAP) at increasing the bioactivity of nitric oxide and related metabolites from skin. Human and mouse skin contain large stores of nitrogen oxides, which are mobilized into the circulation by exposure of skin to sub-erythemal UVR (Geldenhuys et al. 2014, Liu et al. 2014). The precise mechanism for this process is yet to be described. The results of other preclinical studies using eNOS (endothelial nitric oxide synthase)-deficient mice (Nozaki et al. 2015) or chemical inhibitors of eNOS (Sheldon et al. 2015), suggest that nitric oxide can reduce liver steatosis impairing hepatic blood flow (Nozaki et al. 2015) and/or reducing hepatic mitochondrial activity (Sheldon et al. 2015). Further work is required to determine the mechanism(s) through which the skin release of nitric oxide by UVR prevents the excessive accumulation of fat in the liver.

We have previously shown that the effects of UVR on reducing weight gain and the development of signs of metabolic dysfunction in male mice fed a high fat diet are independent of vitamin D (Geldenhuys et al. 2014). Male mice have significantly impaired capacity to increase circulating 25-hydroxyvitamin D levels in response to UVR (Gorman et al. 2012, Geldenhuys et al. 2014, Xue et al. 2015). This may be because male mice have reduced epidermal stores of 7-dehydrocholesterol (Gorman et al. 2012, Xue et al. 2015), which are suppressed in an androgen-specific fashion (Xue et al. 2015). Vitamin D-deficient male mice also have increased renal levels of the vitamin D breakdown enzyme, 24-hydroyxlase (CYP24A1) (Gorman et al. 2012). We previously reported that dietary vitamin $\mathrm{D}_{3}(2280 \mathrm{IU} / \mathrm{kg})$ did not have antiobesogenic effect when administered alone, and when combined with FS40 UVR, dietary vitamin D prevented the suppressive effects of FS40 UVR on weight gain, WAT weight and fasting glucose levels (Geldenhuys et al. 2014). Although dietary vitamin D improved liver steatosis, FS40 UVR was more effective (Geldenhuys et al. 2014). In human epidemiological studies, obesity is associated with poorer vitamin D status, but low 25(OH)D levels may be caused by obesity rather than vice versa (Vimaleswaran et al. 2013). The effects of vitamin D supplementation on improving cardiometabolic function in humans are uncertain with inconclusive results reported in a meta-analyses of randomized controlled trials that tested the efficacy of vitamin D to modulate weight gain (Mallard et al. 2016), cardiovascular disease, stroke, blood pressure, blood lipids and glucose metabolism (Autier et al. 2014).

Feeding C57BL/6J mice a high-fat diet usually increases the extent of hepatic steatosis (Duval et al. 2016, Gavito et al. 2016, Song et al. 2016). However, unlike our previous studies (Geldenhuys et al. 2014), significant liver steatosis was observed in mice fed a low-fat diet (Fig. 4 and Table 3). Similarly, we also observed higher than expected levels of AST in the serum of mice fed the low-fat diet, with levels comparable to those fed the high-fat diet (Table 3). We used the same diets as those in previously published studies, with an identical experimental approach for the mice fed the high- and low-fat diets only (Geldenhuys et al. 2014). Therefore, it is difficult to understand why our previous observations were not reproduced in the current study. Mice were housed in a similar fashion (open-topped cages with 6 mice per cage). However, it is possible that there may have been a different strategy used to breed the mice by our supplier (e.g. age of dams, diet) or through animal handling (e.g. sex of technician/researcher (Sorge et al. 2014)) within our bioresources facility (e.g. time of year of study) that may account for this unexpected observation.

Published by Bioscientifica Ltd. 
The mice in the current study were housed at $21^{\circ} \mathrm{C}$. It would be interesting to determine the effects of regular skin exposure to UVR on the development of obesity in mice housed in warmer, thermoneutral conditions. Thermoneutrality may promote adiposity in mice fed a high-fat diet (Cui et al. 2016). The effects of exposure to sub-erythemal UVA radiation in reducing arterial blood pressure of young adult male volunteers were independent of temperature, with similar increases in the skin temperatures of individuals exposed to the UVA or sham irradiation protocols (Liu et al. 2014). In our studies, we used sub-erythemal doses of UVR, which did not induce edema or burn the skin of the mice. Whether there is an anti-obesogenic role for heat production in the skin after exposure to UVR is uncertain.

In conclusion, our studies demonstrate that lowdose (sub-erythemal) UVR reduces the expression of risk factors of adiposity and cardiometabolic dysfunction in already overweight mice. We observed a reduction in weight gain of $\sim 10 \%$, but a much larger reduction ( $>50 \%$ ) in circulating fasting insulin levels with UVR treatment. These observations are similar to those from weight loss studies in humans, where small weight losses of $\sim 5 \%$ can correspond to significant improvements in insulin sensitivity and reductions in hepatic fat (Magkos et al. 2016). Further work is needed in the form of clinical trials to assess the efficacy of safe sun exposure and/or UVR phototherapy to reduce the cardiometabolic risk in susceptible people.

\section{Supplementary data}

This is linked to the online version of the paper at http://dx.doi.org/10.1530/ JOE-16-0616.

\section{Declaration of interest}

Prof. Feelisch and Dr Weller are members of the Scientific Advisory Board of AOBiome LLC, a company commercializing ammonia-oxidizing bacteria for use in inflammatory skin disease. Dr Weller is also a Director of and Prof. Feelisch a Scientific Advisor for RelaxSol Ltd, a company developing novel sunscreen and skincare products. We have no further disclosures or conflicts of interest to declare.

\section{Funding}

This research was supported by the Rebecca L Cooper Foundation, the Diabetes Research Foundation of Western Australia, the Department of Health of Western Australia, the University of Western Australia and the Telethon Kids Institute.

\section{Author contribution statement}

$S \mathrm{G}$ conceived and designed this study with input from N F, M F, P H H, R B W, J S and V M. N F acquired and analyzed the data for the study with help from J S and S G. All authors have contributed toward the interpretation of findings from this study, have played a role in drafting the article or revising it critically for its intellectual content and have given their final approval for this version of the paper to be published.

\section{Acknowledgements}

Thank you to Denise Anderson (Telethon Kids Institute) for statistical advice; Maxine Crook (Princess Margaret Hospital Pathology, Subiaco, Western Australia) and Luke Berry (Telethon Kids Institute) for preparing the histological liver sections; and Linda Gregory (PathWest Laboratory at Royal Perth Hospital, Perth, WA) for performing the serum cholesterol, HDL cholesterol, LDL cholesterol, triglyceride and AST assays.

\section{References}

Al-Daghri NM, Alkharfy KM, Al-Saleh Y, Al-Attas OS, Alokail MS, Al-Othman A, Moharram O, El-Kholie E, Sabico S, Kumar S, et al. 2012 Modest reversal of metabolic syndrome manifestations with vitamin D status correction: a 12-month prospective study. Metabolism 61 661-666. (doi:10.1016/j.metabol.2011.09.017)

Autier P, Boniol M, Pizot C \& Mullie P 2014 Vitamin D status and ill health: a systematic review. Lancet Diabetes and Endocrinology 2 76-89. (doi:10.1016/S2213-8587(13)70165-7)

Baldassarre D, Nyyssonen K, Rauramaa R, de Faire U, Hamsten A, Smit AJ, Mannarino E, Humphries SE, Giral P, Grossi E, et al. 2010 Crosssectional analysis of baseline data to identify the major determinants of carotid intima-media thickness in a European population: the IMPROVE study. European Heart Journal 31 614-622. (doi:10.1093/ eurheartj/ehp496)

Clark JM 2006 The epidemiology of nonalcoholic fatty liver disease in adults. Journal of Clinical Gastroenterology $\mathbf{4 0}$ (Supplement 1) S5-S10.

Colas C, Garabedian M, Fontbonne A, Guillozo H, Slama G, Desplanque N, Dauchy F \& Tchobroutsky G 1989 Insulin secretion and plasma 1,25- $(\mathrm{OH}) 2 \mathrm{D}$ after UV-B irradiation in healthy adults. Hormone and Metabolic Research 21 154-155. (doi:10.1055/s-2007-1009178)

Cui X, Nguyen NL, Zarebidaki E, Cao Q, Li F, Zha L, Bartness T, Shi H \& Xue B 2016 Thermoneutrality decreases thermogenic program and promotes adiposity in high-fat diet-fed mice. Physiological Reports 4 e12799. (doi:10.14814/phy2.12799)

de Winter S, Vink AA, Roza L \& Pavel S 2001 Solar-simulated skin adaptation and its effect on subsequent UV-induced epidermal DNA damage. Journal of Investigative Dermatology 117 678-682. (doi:10.1046/j.0022-202x.2001.01478.x)

Doro P, Grant WB, Benko R, Matuz M, Toth T \& Soos G 2008 Vitamin D and the seasonality of type 2 diabetes. Medical Hypotheses 71 317-318. (doi:10.1016/j.mehy.2008.03.005)

Duval C, Teixeira-Clerc F, Leblanc AF, Touch S, Emond C, Guerre-Millo M, Lotersztajn S, Barouki R, Aggerbeck M \& Coumoul X 2016 Chronic exposure to low doses of dioxin promotes liver fibrosis development in the C57BL6/J diet-induced obesity mouse model. Environmental Health Perspectives [in press]. (doi:10.1289/ehp316)

Earthman CP, Beckman LM, Masodkar K \& Sibley SD 2012 The link between obesity and low circulating 25-hydroxyvitamin D concentrations: considerations and implications. International Journal of Obesity 36 387-396. (doi:10.1038/ijo.2011.119) http://joe.endocrinology-journals.org DOI: 10.1530/JOE-16-0616
๑ 2017 Society for Endocrinology Printed in Great Britain
Published by Bioscientifica Ltd 
Feelisch M, Gorman S \& Weller RB 2014 Vitamin D status and ill health. Lancet Diabetes and Endocrinology 2 e8. (doi:10.1016/S22138587(14)70043-9)

Fleury N, Geldenhuys S \& Gorman S 2016 Sun exposure and its effects on human health: mechanisms through which sun exposure could reduce the risk of developing obesity and cardiometabolic dysfunction. International Journal of Environmental Research and Public Health 13 999. (doi:10.3390/ijerph13100999)

Gavito AL, Bautista D, Suarez J, Badran S, Arco R, Pavon FJ, Serrano A, Rivera P, Decara J, Cuesta AL, et al. 2016 Chronic IL-6 administration desensitizes IL-6 response in liver, causes hyperleptinemia and aggravates steatosis in diet-induced-obese mice. PLOS ONE 11 e0157956. (doi:10.1371/journal.pone.0157956)

Geldenhuys S, Hart PH, Endersby R, Jacoby P, Feelisch M, Weller RB, Matthews V \& Gorman S 2014 Ultraviolet radiation suppresses obesity and symptoms of metabolic syndrome independently of vitamin D in mice fed a high-fat diet. Diabetes 63 3759-3769. (doi:10.2337/db13-1675)

Gorman S, Tan JW, Yerkovich ST, Finlay-Jones JJ \& Hart PH 2007 CD4+ T cells in lymph nodes of UVB-irradiated mice suppress immune responses to new antigens both in vitro and in vivo. Journal of Investigative Dermatology 127 915-924. (doi:10.1038/sj.jid.5700600)

Gorman S, Scott NM, Tan DH, Weeden CE, Tuckey RC, Bisley JL, Grimbaldeston MA \& Hart PH 2012 Acute erythemal ultraviolet radiation causes systemic immunosuppression in the absence of increased 25-hydroxyvitamin D3 levels in male mice. PLOS ONE 7 e46006. (doi:10.1371/journal.pone.0046006)

Grau M, Guxens M, Subirana I, Fito M, Covas MI, Jacquemin B, Sunyer J, Lanki T, Picciotto S, Bellander T, et al. 2007 South-to-North gradient in lipid peroxidation in men with stable coronary artery disease in Europe. European Heart Journal 28 2841-2849. (doi:10.1093/eurheartj/ ehm446)

Hirschler V 2016 Cardiometabolic risk factors in native populations living at high altitudes. International Journal of Clinical Practice $\mathbf{7 0}$ 113-118. (doi:10.1111/ijcp.12756)

Holick MF, Chen TC, Lu Z \& Sauter E 2007 Vitamin D and skin physiology: a D-lightful story. Journal of Bone and Mineral Research 22 (Supplement 2) V28-V33. (doi:10.1359/jbmr.07s211)

Hurson M, Regan MC, Kirk SJ, Wasserkrug HL \& Barbul A 1995 Metabolic effects of arginine in a healthy elderly population. Journal of Parenteral and Enteral Nutrition 19 227-230. (doi:10.1177/014860719 5019003227)

Ikeyama K, Fuziwara S \& Denda M 2007 Topical application of neuronal nitric oxide synthase inhibitor accelerates cutaneous barrier recovery and prevents epidermal hyperplasia induced by barrier disruption. Journal of Investigative Dermatology 127 1713-1719. (doi:10.1038/ sj.jid.5700742)

Kleiner DE, Brunt EM, Van Natta M, Behling C, Contos MJ, Cummings OW, Ferrell LD, Liu YC, Torbenson MS, UnalpArida A, et al. 2005 Design and validation of a histological scoring system for nonalcoholic fatty liver disease. Hepatology 41 1313-1321. (doi:10.1002/hep.20701)

Krause R, Buhring M, Hopfenmuller W, Holick MF \& Sharma AM 1998 Ultraviolet B and blood pressure. Lancet 352 709-710. (doi:10.1016/ S0140-6736(05)60827-6)

Kunes J, Tremblay J, Bellavance F \& Hamet P 1991 Influence of environmental temperature on the blood pressure of hypertensive patients in Montreal. American Journal of Hypertension 4 422-426. (doi:10.1093/ajh/4.5.422)

Lindqvist PG, Epstein E \& Olsson H 2009 Does an active sun exposure habit lower the risk of venous thrombotic events? A D-lightful hypothesis. Journal of Thrombosis and Haemostasis 7 605-610. (doi:10.1111/j.1538-7836.2009.03312.x)

Lindqvist PG, Olsson H \& Landin-Olsson M 2010 Are active sun exposure habits related to lowering risk of type 2 diabetes mellitus in women, a prospective cohort study? Diabetes Research and Clinical Practice 90 109-114. (doi:10.1016/j.diabres.2010.06.007)

Lindqvist PG, Epstein E, Landin-Olsson M, Ingvar C, Nielsen K, Stenbeck M \& Olsson H 2014 Avoidance of sun exposure is a risk factor for all-cause mortality: results from the Melanoma in Southern Sweden cohort. Journal of Internal Medicine 276 77-86. (doi:10.1111/joim.12251)

Liu D, Fernandez BO, Hamilton MB, Lang NN, Gallagher JMC, Newby DE, Feelisch M \& Weller RB 2014 UVA irradiation of human skin vasodilates arterial vasculature and lowers blood pressure independently of nitric oxide synthase. Journal of Investigative Dermatology 134 1839-1846. (doi:10.1038/jid.2014.27)

Magkos F, Fraterrigo G, Yoshino J, Luecking C, Kirbach K, Kelly SC, de Las Fuentes L, He S, Okunade AL, Patterson BW, et al. 2016 Effects of moderate and subsequent progressive weight loss on metabolic function and adipose tissue biology in humans with obesity. Cell Metabolism 23 591-601. (doi:10.1016/j.cmet.2016.02.005)

Mallard SR, Howe AS \& Houghton LA 2016 Vitamin D status and weight loss: a systematic review and meta-analysis of randomized and nonrandomized controlled weight-loss trials. American Journal of Clinical Nutrition 104 1151-1159. (doi:10.3945/ajcn.116.136879)

McGlade JP, Gorman S, Zosky GR, Larcombe AN, Sly PD, Finlay-Jones JJ, Turner DJ \& Hart PH 2007 Suppression of the asthmatic phenotype by ultraviolet B-induced, antigen-specific regulatory cells. Clinical and Experimental Allergy 37 1267-1276. (doi:10.1111/j.13652222.2007.02750.x)

Nakano T, Cheng YF, Lai CY, Hsu LW, Chang YC, Deng JY, Huang YZ, Honda H, Chen KD, Wang CC, et al. 2011 Impact of artificial sunlight therapy on the progress of non-alcoholic fatty liver disease in rats. Journal of Hepatology 55 415-425. (doi:10.1016/j.jhep.2010.11.028)

Narbutt J, Lesiak A, Skibinska M, Wozniacka A, van Loveren H, SysaJedrzejowska A, Lewy-Trenda I, Omulecka A \& Norval M 2005 Suppression of contact hypersensitivity after repeated exposures of humans to low doses of solar simulated radiation. Photochemical and Photobiological Sciences 4 517-522. (doi:10.1039/b503166d)

Ng RL, Scott NM, Strickland DH, Gorman S, Grimbaldeston MA, Norval M, Waithman J \& Hart PH 2013 Altered immunity and dendritic cell activity in the periphery of mice after long-term engraftment with bone marrow from ultraviolet-irradiated mice. Journal of Immunology 190 5471-5484. (doi:10.4049/ jimmunol.1202786)

Nozaki Y, Fujita K, Wada K, Yoneda M, Shinohara Y, Imajo K, Ogawa Y, Kessoku T, Nakamuta M, Saito S, et al. 2015 Deficiency of eNOS exacerbates early-stage NAFLD pathogenesis by changing the fat distribution. BMC Gastroenterology 15 177. (doi:10.1186/s12876-0150409-9)

Ohn JH, Kwon IH, Park J, Ryu OH, Lee SJ, Kim DM, Ihm SH, Choi MG, Yoo HJ \& Hong EG 2014 Unprotected daily sun exposure is differently associated with central adiposity and beta-cell dysfunction by gender: the Korean National Health and Nutrition Examination Survey (KNHANES) V. Environmental Research 133 253-259. (doi:10.1016/j. envres.2014.05.033)

Osmancevic A, Nilsen LT, Landin-Wilhelmsen K, Soyland E, Abusdal Torjesen P, Hagve TA, Nenseter MS \& Krogstad AL 2009 Effect of climate therapy at Gran Canaria on vitamin D production, blood glucose and lipids in patients with psoriasis. Journal of the European Academy of Dermatology and Venereology 23 1133-1140. (doi:10.1111/ j.1468-3083.2009.03245.x)

Pothiawala S, Qureshi AA, Li Y \& Han J 2012 Obesity and the incidence of skin cancer in US Caucasians. Cancer Causes and Control 23 717-726. (doi:10.1007/s10552-012-9941-x)

Rostand SG 1997 Ultraviolet light may contribute to geographic and racial blood pressure differences. Hypertension 30 150-156. (doi:10.1161/01.HYP.30.2.150)

Scragg R, Wishart J, Stewart A, Ofanoa M, Kerse N, Dyall L \& Lawes CM 2011 No effect of ultraviolet radiation on blood pressure and other http://joe.endocrinology-journals.org

DOI: $10.1530 / J O E-16-0616$
๑ 2017 Society for Endocrinology Printed in Great Britain 
cardiovascular risk factors. Journal of Hypertension 29 1749-1756. (doi:10.1097/HJH.0b013e328349666d)

Sheldon RD, Padilla J, Jenkins NT, Laughlin MH \& Rector RS 2015 Chronic NOS inhibition accelerates NAFLD progression in an obese rat model. American Journal of Physiology: Gastrointestinal and Liver Physiology 308 G540-G549. (doi:10.1152/ajpgi.00247.2014)

Shore-Lorenti C, Brennan SL, Sanders KM, Neale RE, Lucas RM \& Ebeling PR 2014 Shining the light on Sunshine: a systematic review of the influence of sun exposure on type 2 diabetes mellitus-related outcomes. Clinical Endocrinology 81 799-811. (doi:10.1111/cen.12567)

Sohmiya M, Kanazawa I \& Kato Y 2004 Seasonal changes in body composition and blood HbA1c levels without weight change in male patients with type 2 diabetes treated with insulin. Diabetes Care $\mathbf{2 7}$ 1238-1239. (doi:10.2337/diacare.27.5.1238)

Song H, Lai J, Tang Q \& Zheng X 2016 Mulberry ethanol extract attenuates hepatic steatosis and insulin resistance in high-fat diet-fed mice. Nutrition Research 36 710-718. (doi:10.1016/j. nutres.2016.01.011)

Sorge RE, Martin LJ, Isbester KA, Sotocinal SG, Rosen S, Tuttle AH, Wieskopf JS, Acland EL, Dokova A, Kadoura B, et al. 2014 Olfactory exposure to males, including men, causes stress and related analgesia in rodents. Nature Methods 11 629-632. (doi:10.1038/nmeth.2935)

Tang JY, Henderson MT, Hernandez-Boussard T, Kubo J, Desai M, Sims ST, Aroda V, Thomas F, McTiernan A \& Stefanick ML 2013 Lower skin cancer risk in women with higher body mass index: the women's health initiative observational study. Cancer Epidemiology, Biomarkers and Prevention 22 2412-2415. (doi:10.1158/1055-9965.EPI-13-0647)

Vimaleswaran KS, Berry DJ, Lu C, Tikkanen E, Pilz S, Hiraki LT, Cooper JD, Dastani Z, Li R, Houston DK, et al. 2013 Causal relationship between obesity and vitamin $\mathrm{D}$ status: bi-directional Mendelian randomization analysis of multiple cohorts. PLoS Medicine 10 e1001383. (doi:10.1371/journal.pmed.1001383)

Woodhouse PR, Khaw KT \& Plummer M 1993 Seasonal variation of blood pressure and its relationship to ambient temperature in an elderly population. Journal of Hypertension 11 1267-1274. (doi:10.1097/00004872-199311000-00015)

Xue Y, Ying L, Horst RL, Watson G \& Goltzman D 2015 Androgens attenuate vitamin $\mathrm{D}$ production induced by UVB irradiation of the skin of male mice by an enzymatic mechanism. Journal of Investigative Dermatology 135 3125-3132. (doi:10.1038/jid.2015.297)

Yasukawa K, Tokuda H, Tun X, Utsumi H \& Yamada K 2012 The detrimental effect of nitric oxide on tissue is associated with inflammatory events in the vascular endothelium and neutrophils in mice with dextran sodium sulfate-induced colitis. Free Radical Research 46 1427-1436. (doi:10.3109/10715762.2012.732698)

Zittermann A \& Gummert JF 2010 Sun, vitamin D, and cardiovascular disease. Journal of Photochemistry and Photobiology B 101 124-129. (doi:10.1016/j.jphotobiol.2010.01.006)

Received in final form 2 December 2016

Accepted 1 February 2017

Accepted Preprint published online 2 February 2017
๑) 2017 Society for Endocrinology Printed in Great Britain 